\title{
Liver transplantation for alcoholic liver disease: A devilish dilemma
}

\author{
Stephen E Congly MD FRCPC, Samuel S Lee MD FRCPC
}

O thou invisible

Spirit of wine, if thou hast no name to be known by,

Let us call thee devil!

$$
\text { - William Shakespeare, Othello }
$$

A lcohol has been with us virtually since the dawn of human existence, when cavemen must have discovered that fermenting certain substances produced a pleasurably mood-altering beverage. Therein lies the dilemma and dichotomy of alcohol, which in modest amounts is generally regarded to be a pleasant experience, but consumed excessively, either acutely or chronically, inflicts terrible physical, emotional and mental havoc. Thus, some global regions have banned the 'devil's drink' altogether, whereas in most societies, including Canada, it is associated with curious, often paradoxical sociocultural attitudes. On one hand, drinking modest amounts is encouraged when socializing or as part of a 'fine dining' experience. On the other hand, excessive drinking, especially chronically, thus leading to emotional and physical addiction, is often associated with joblessness, homelessness and social isolation, in addition to the terrible physical ailments well known to readers of this Journal. Despite the massive physical, mental and emotional degradation in those addicted to alcohol, there is little sympathy for these individuals society generally regards them with derision and contempt.

The recognition that alcoholism is a disease, and deserving of sympathy and unbiased treatment, is a cornerstone of medical management. However, many conflicting pressures and complexities arise when discussing allocation of health care resources to patients afflicted with this disease. Indeed, allocation of a very limited resource is one of the most difficult ethical challenges associated with transplantation. Demand constantly exceeds supply, with approximately $16 \%$ of listed patients dying on the wait list in Canada from 2000 to 2010 (1) and similar numbers in the United States (2). Currently in Canada, alcohol is the second most common primary indication for transplantation after hepatitis $\mathrm{C}$ virus (HCV) infection, and is the third most common indication in the United States. Alcohol likely plays a more significant role if secondary and tertiary etiologies for end-stage liver disease (ESLD) are accounted for (ie, HCV-infected individuals are more likely to progress to ESLD if they drink heavily).

Transplantation for alcoholic liver disease (ALD) has been controversial, with arguments being made that they are less deserving of transplantation due to the behavioural component and the popular perception of the person 'doing it to themself' $(3,4)$. Further complicating matters is that surveys of the general public and nontransplant physicians illustrate feelings that ALD is a lower priority for transplantation (5), which may contribute to under-referral of patients with ALD for transplant evaluation (6). However, there is no moral argument to argue that alcoholic liver disease should preclude a person from potential transplantation (7) given other 'behavioural-driven' liver diseases, including HCV infection acquired from previous intravenous drug use or nonalcoholic fatty liver disease due to obesity.

In the current issue of the Canadian Journal of Gastroenterology, Chandok et al (8) (pages 643-646) investigated practices for transplantation for ALD across Canada as a method to evaluate the standard of care in the country. All of the seven transplant programs were surveyed with regard to pretransplant evaluation and monitoring of patients listed for ESLD secondary to alcohol as well as views regarding transplantation for alcoholic hepatitis. Nationwide, the unifying standards are that of requiring a minimum of six months of abstinence before listing for a liver transplant and not transplanting individuals with alcoholic hepatitis. No program uses a validated alcohol-screening tool as a mandatory component of the assessment. Only one program performs random screens of patients awaiting transplantation and one requires completion of a formal alcohol rehabilitation program.

The study by Chandok et al (8) raises several challenging questions with regard to policies in transplantation of patients with alcoholic cirrhosis. Given that alcoholism is an addiction, there is a risk of relapse post-transplantation with a variable extent of use. Repeat use of alcohol is apparent in $27 \%$ to $40 \%$ of individuals transplanted for ALD, with significantly impaired long-term survival (9-11). Clearly, selecting the appropriate transplant candidates is critical. In North America, the vast majority of programs currently require at least six months of abstinence (12). The six-month period was originally developed to both gauge the degree of reversibility of liver disease with abstinence and to demonstrate a period of time without addiction, although its prognostication ability has not been consistently demonstrated (13). Nonetheless, although results are not universal (14), the majority of the literature supports that with shorter periods of abstinence, the relapse rate is higher (11) and, concordantly, lower rates of recidivism the longer the period of abstinence, although there is no magic cut-off value (15).

Given the association of abstinence with outcomes and the rate of returning to alcohol, monitoring potential alcohol use is important. Patient history is unreliable: in one series (16), 38\% of listed patients with ALD were shown to have alcohol in their urine, with only $4 \%$ directly admitting to use. Random alcohol screens performed for patients listed for transplant due to ALD in one Canadian centre showed $17 \%$ using alcohol (17); random screening is better than scheduled screening for identifying illicit alcohol use (18).

Historically, alcoholic hepatitis has been a contraindication for transplantation due to concerns with high relapse rates and poor outcomes; one retrospective database evaluation of transplantation in the United States suggested similar outcomes compared with alcoholic cirrhosis, although numbers were small (19). Publication of a study by Mathurin et al (20) in the New England Journal of Medicine two years ago created significant 'buzz' in the transplant world. It reported a seven-centre French prospective study of early transplantation for severe alcoholic hepatitis, and it showed a survival benefit in 26 transplants of treatment nonresponders, with a six-month survival rate of $77 \%$. This group was transplanted within 11 days and this population accounted for $3 \%$ of all the grafts used. An important caveat is that this cohort was very highly selected, representing $<2 \%$ of all patients admitted to the seven centres with alcoholic hepatitis. Therefore, they required an extremely intensive system of evaluation; in spite of this, $11 \%$ returned to alcohol use. In comparison, expected one-year survival outcomes of transplantation are $90 \%(1,2)$ while the one-year survival rate after transplantation for fulminant liver failure is

University of Calgary Liver Unit, Calgary, Alberta

Correspondence: Dr Samuel S Lee, University of Calgary Liver Unit, 3330 Hospital Drive Northwest, Calgary, Alberta T2N 4 N1.

Telephone 403-220-8457, fax 403-270-0995, e-mail samlee@ucalgary.ca

Received and accepted for publication October 3, 2013 
approximately $70 \%$ (21). Despite the intriguing results of that study, the extreme degree of selection markedly limits the general clinical applicability of the findings; therefore, they must be interpreted with caution.

The Chandok et al (8) article states that all seven Canadian adult transplant programs were interested in further discussing the key question of whether to transplant alcoholic hepatitis without the sixmonth abstinence period. However, that is curiously at odds with the results of intense discussion at the Canadian Liver Transplant Network meeting held in Banff, Alberta, in March 2013 (all Canadian transplant centres are part of this network). One program proposed the idea of trying to replicate the study by Mathurin et al (20); however, after much discussion, this idea did not move forward due to lack of support (D Marleau, Université de Montréal, Montréal, Québec, personal communication, 2013).

The study by Chandok et al (8) highlights some of the challenges with transplantation in ALD, and the similarities and differences across the country. Determining the best transplant candidates and treatment of addiction are cornerstones of patient management and

\section{REFERENCES}

1. CIHI. Canadian Organ Replacement Register Annual Report: Treatment of End-Stage Organ Failure in Canada, 2001 to 2010. Ottawa: 2011.

2. Kim WR, Stock PG, Smith JM, et al. OPTN/SRTR 2011 Annual Data Report: Liver. Am J Transplant 2013;13(Suppl 1):73-102.

3. Glannon W. Responsibility, alcoholism, and liver transplantation. J Med Philos 1998;23:31-49.

4. Moss AH, Siegler M. Should alcoholics compete equally for liver transplantation? JAMA 1991;265:1295-8.

5. Neuberger J. Public and professional attitudes to transplanting alcoholic patients. Liver Transpl 2007;13:S65-S68.

6. Kotlyar DS, Burke A, Campbell MS, Weinrieb RM. A critical review of candidacy for orthotopic liver transplantation in alcoholic liver disease. Am J Gastroenterol 2008;103:734-43.

7. Cohen C, Benjamin M. Alcoholics and liver transplantation. The Ethics and Social Impact Committee of the Transplant and Health Policy Center. JAMA 1991;265:1299-301.

8. Chandok N, Aljawad M, White A, Hernandez-Alejandro R, Marotta P, Yoshida EM. Liver transplantation for alcoholic liver disease among Canadian transplant centres: A national study. Can J Gastroenterol 2013;27:643-6.

9. Faure S, Herrero A, Jung B, et al. Excessive alcohol consumption after liver transplantation impacts on long-term survival, whatever the primary indication. J Hepatol 2012;57:306-12.

10. Schmeding M, Heidenhain C, Neuhaus R, Neuhaus P, Neumann UP. Liver transplantation for alcohol-related cirrhosis: A single centre long-term clinical and histological follow-up. Dig Dis Sci 2011;56:236-43.

11. Pfitzmann R, Schwenzer J, Rayes N, Seehofer D, Neuhaus R, Nüssler NC. Long-term survival and predictors of relapse after orthotopic liver transplantation for alcoholic liver disease. Liver Transpl 2007;13:197-205. maximizing organ utility. We acknowledge that the 'six-month rule' is arbitrary, but argue that this restriction is "demonstrably justified in a free and democratic society" given the limited availability of grafts until better predictive tools can be applied toward selecting transplant candidates. Increased testing of patients on the wait list may help in targeting addiction treatments to higher-risk individuals and act as a predictive tool for substance relapse. Although transplanting alcoholic hepatitis may improve the individual outcome, there is both increased organ use and a lower survival rate, which in turn will impact others on the wait list. The literature supporting transplantation for this indication also featured a very highly selected group of patients with intensive evaluation that may further burden programs. Finally, transplantation for acute alcoholic hepatitis may also expose new challenges because any period of required abstinence before transplant would then be difficult to rationalize. Overall, national guidelines for transplantation for ALD would be welcome so as to ensure that no person is disadvantaged on account of policy from a transplant standpoint based on which area of the country they are from.

12. Kroeker KI, Bain VG, Shaw-Stiffel T, Fong T-L, Yoshida EM. Adult liver transplant survey: Policies towards eligibility criteria in Canada and the United States 2007. Liver Int 2008;28:1250-5.

13. Tan $\mathrm{H}-\mathrm{H}$, Virmani S, Martin P. Controversies in the management of alcoholic liver disease. Mt Sinai J Med 2009;76:484-98.

14. Kelly M, Chick J, Gribble R, et al. Predictors of relapse to harmful alcohol after orthotopic liver transplantation. Alcohol Alcohol 2006;41:278-83.

15. DiMartini A, Day N, Dew MA, et al. Alcohol consumption patterns and predictors of use following liver transplantation for alcoholic liver disease. Liver Transpl 2006;12:813-20.

16. Webzell I, Ball D, Bell J, et al. Substance use by liver transplant candidates: An anonymous urinalysis study. Liver Transpl 2011;17:1200-4

17. Carbonneau M, Jensen LA, Bain VG, Kelly K, Meeberg G, Tandon P. Alcohol use while on the liver transplant waiting list: A single-center experience. Liver Transpl 2010;16:91-7.

18. Bholah H, Bate J, Rothwell K, Aldersley M. Random blood alcohol level testing detects concealed alcohol ingestion in patients with alcoholic liver disease awaiting liver transplantation. Liver Transpl 2013;19:782-3.

19. Singal AK, Bashar H, Anand BS, Jampana SC, Singal V, Kuo Y-F. Outcomes after liver transplantation for alcoholic hepatitis are similar to alcoholic cirrhosis: Exploratory analysis from the UNOS database. Hepatology 2012;55:1398-405.

20. Mathurin P, Moreno C, Samuel D, et al. Early liver transplantation for severe alcoholic hepatitis. N Engl J Med 2011;365:1790-800.

21. Fontana RJ. Acute liver failure including acetaminophen overdose. Med Clin North Am 2008;92:761-94, viii. 


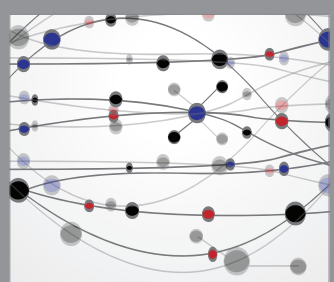

The Scientific World Journal
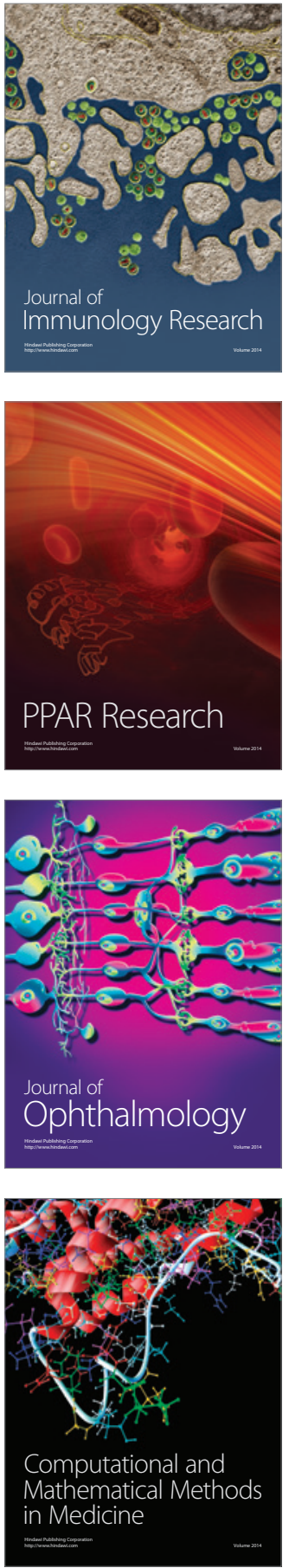

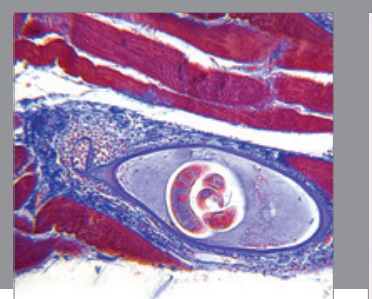

Gastroenterology Research and Practice

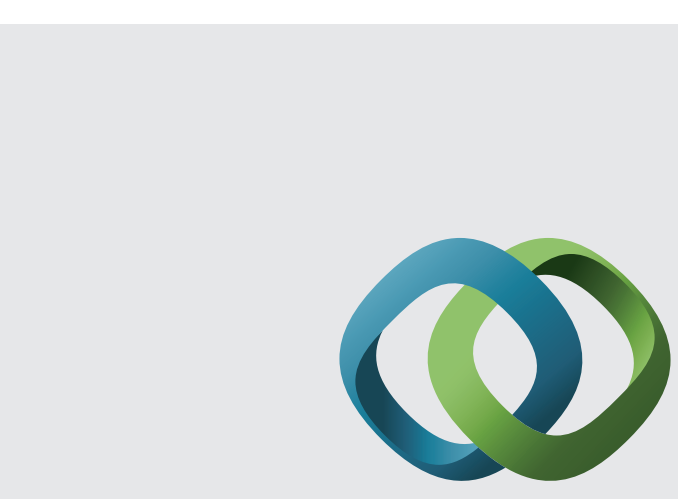

\section{Hindawi}

Submit your manuscripts at

http://www.hindawi.com
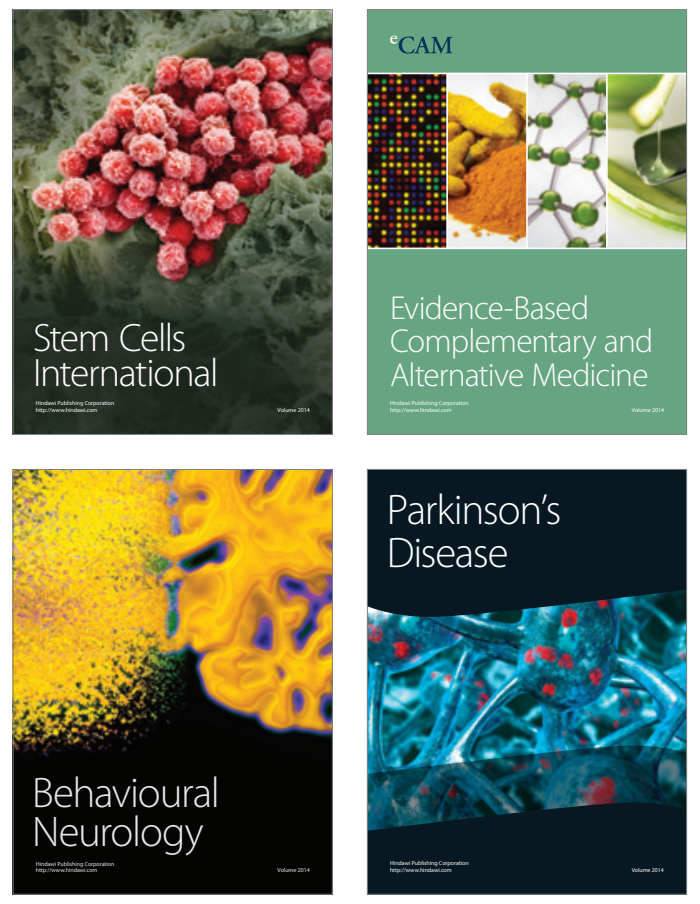
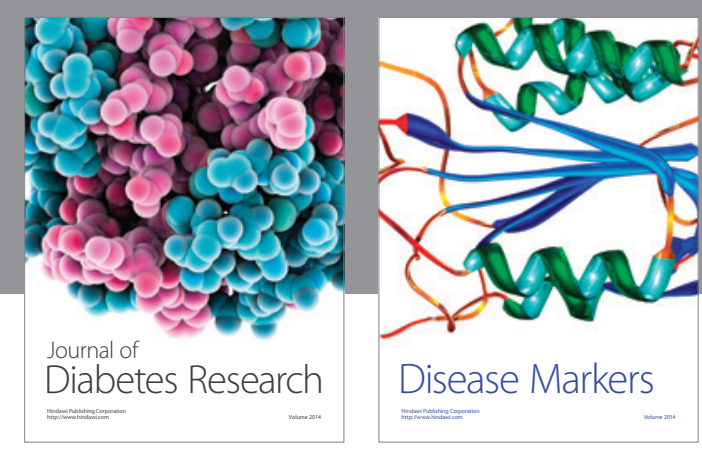

Disease Markers
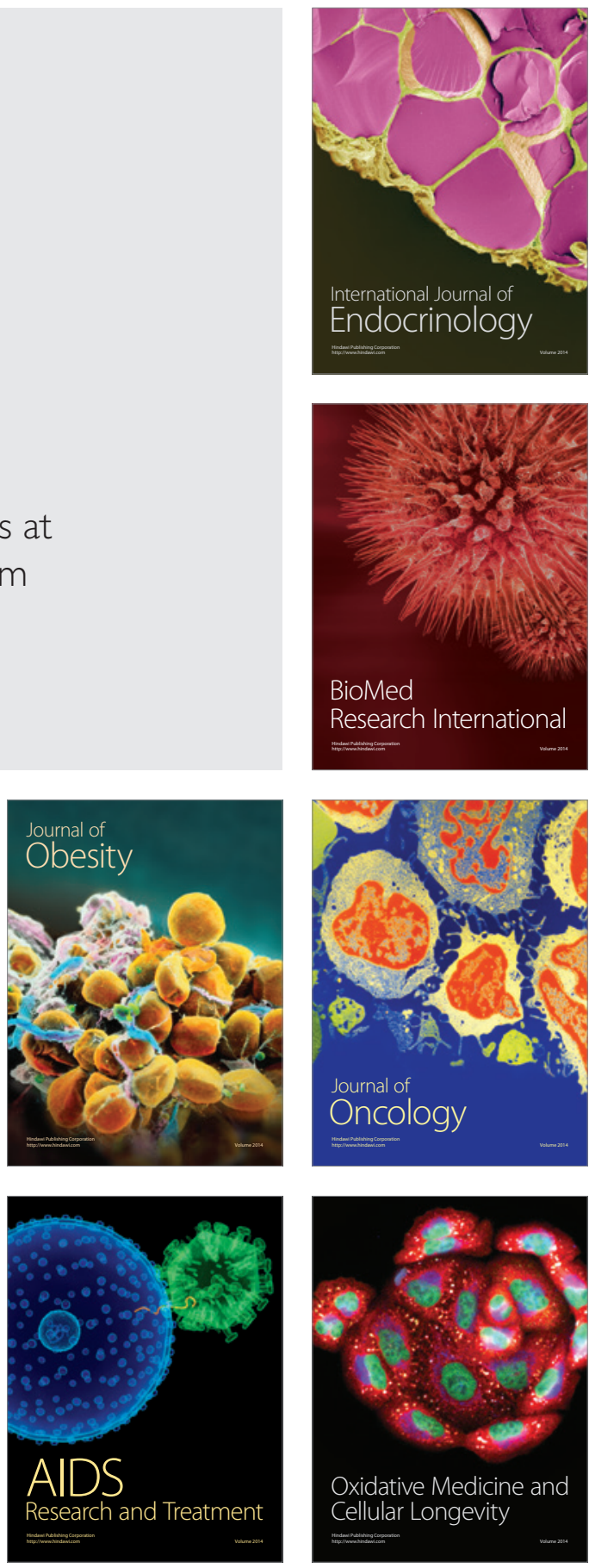